\title{
Comment Domain
}

National Cancer Institute

\section{Source}

National Cancer Institute. Comment Domain. NCI Thesaurus. Code C49569.

A subject domain utilized for the submission of information encompassing and representing data, vocabulary or records related to comments. 